below the kidney. The patient stood the operation well and promised at first to make a good recovery ; she sank, however, five days after the operation, apparently from exhaustion. There were troublesome vomiting and slight distension unrelieved by salines or enemata. As far as the wound went all was satisfactory and there was no extravasation. The gall-bladder was shut off from the general peritoneal cavity and there were no signs of general peritonitis.

Remarks by Mr. NEwBoLT. - In those cases in which a stone ulcerates through the gall-bladder mischief is usually avoided by the adhesions which glue the affected organ to neighbouring parts, either the viscera or the abdominal wall. There are several cases on record by different observers in which acute peritonitis has been set up by a perforation of the gall-bladder the contents of which have escaped into the abdominal cavity, and there are one or two instances also which have been successfully operated upon. In the case related above it was impossible to make a diagnosis from perforated gastric ulcer and for this reason, though the result was fatal, I think that it is desirable to publish it. A close interrogation of the patient never elicited any history of gallstones and she had always referred her pain to the region of the stomach. She had never been jaundiced at any time and was most definite on this point.

\section{ROYAL NAVAL HOSPITAL, PLYMOUTH.}

A CASE OF MULTIPLE ABSCESSES IN THE LIVER SECONDARY TO PERFORATING ULCER OF THE STOMACH.

(Under the care of Staff-Surgeon EDWARD R. D. FASKEN, R.N.)

Multiple abscess of the liver is a very rare complication of gastric ulcer, whether perforated or unperforated, and very few cases have been put on record. C. Murchison has published an instance of this condition ${ }^{1}$ but in that case general pyæmia also occurred. In the following case no signs or symptoms pointed to the existence of gastric ulcer. This latency occurs in no small proportion of cases. Savariand ${ }^{2}$ estimated the latent cases to form 20 per cent. of all cases of gastric ulcer.

On Feb. 22nd. 1902, an able seaman was admitted into the Royal Naval Hospital, Plymouth, under the care of StaffSurgeon Fasken, complaining that he had suffered from abdominal pain on or off for about two years, situated chiefly in the right iliac fossa near the umbilicus. The bowels were acting irregularly. There was no history of vomiting. The temperature was $102^{\circ} \mathrm{F}$. The hepatic dulness in the right mammary line measured five inches vertically. There was considerable jaundice. The pulse was 76. The abdomen was somewhat distended and palpation caused a good deal of pain, especially over the cæcum. The tongue was thickly coated. Fomentations and a glycerine enema were prescribed with bismuth and the patient was placed on a milk diet. On the evening of March 1st he had a rigor and complained of severe pain over the hepatic area. The temperature was $102 \cdot 2^{\circ}$. On the $3 \mathrm{rd}$ he had more rigors and complained of a tender spot over the liver in the region of the gall-bladder. Paroxysmal rigors came on at irregular intervals and were followed by profuse perspiration with great prostration. The tongue became dry and brown and tenderness over the liver area was greatly increased. On the $22 n d$ he vomited a quantity of greenish bilious fluid during the night. Two exploratory punctures were made into the liver below the costal margin but only a few drops of blood were extracted. On the 24 th two more exploratory punctures were made behind in the eighth intercostal space, but again with a negative result. A few days later ascites and cedema of the lower extremities appeared, also a distinct pleuritic rub was heard on the right side. The hepatic dulness in the right mammary line was now six and a half inches, but the enlargement was uniform and free from nodulation. On April 10th he was much weaker and greatly emaciated. The skin and conjunctivæ were markedly jaundiced. There was great tenderness on pressure below the lower margin of the right ribs, with incessant severe pain across the upper part of the abdomen and between the shoulders, which had to be relieved by injections of morphia. The area of splenic dulness was increased. The above symptoms all became gradually more aggravated. still had irregular paroxysms of rigors, followed by fever and sweating. He gradually sank and died on the 15th.

Necropsy. - At the post-mortem examination there was found near the cesophageal end of the stomach on its anterior surface a circular ulcer of the size of half a crown with its edges slightly elevated and undermined. From the base of this ulcer a small fistulous channel passed into an abscess of the size of a hen's egg in the right lobe of the liver close to the gall-bladder. The liver was enlarged generally, weighing 96 ounces; both lobes were thickly studded with abscesses varying from the size of a pea to that of a walnut and containing thick yellow pus; the abscess cavity in connexion with the stomach was, however, filled with food material. The intervening hepatic tissue was very hyperæmic. There was evidence of considerable surrounding peritoneal inflammation; the stomach, transverse colon, duodenum, pancreas, and liver (the under surface) were all firmly matted together, the great omentum being adherent to the upper surface of the left lobe of the liver. The spleen was large, dark, and firm. The pancreas was hard and lumpy and was firmly adherent to the left kidney and spleen. The abdomen contained a quart of yellowish serons fluid. The right pleural cavity contained fluid and was encroached upon by the enlarged liver, the right lung being pushed up and collapsed and adherent at the base. The other organs were healthy.

Remarks by Staff-Surgeon FASKEx.-This case is of interest, as although the symptoms pointed to the probability of a pyæmic abscess in the liver, inasmuch as the patient had never been abroad, nothing in the history of the case led one to suspect ulceration of the stomach. There had never been any hæmatemesis or even definite history of vomiting, the only symptom complained of being general abdominal pain.

\section{Mttedital Soxietries.}

\section{ROYAL MEDICAL AND CHIRURGICAL SOCIETY.}

The Etiology of Leprosy as observed in the Soudan and in Sonth Africa.

A MEETING of this society was held on May 27th, Mr. ALFRED WrLleTt, the President, being in the chair.

Mr. T. J. ToNkrN made a communication on Some General and Etiological Details concerning Leprosy in the Soudan. Mr. Tonkin began his paper by defining briefly the particular leper area referred to-namely, the Soudan-and by giving a short sketch illustrative of the extent to which the disease prevailed there. Enormous quantities of the disease were to be found in the Soudan and northern Nigeria-an area of 500,000 square miles. He then passed on to describe what he believed to be the ordinary course of contagion in the Soudan. He had satisfied himself that it was a process of mediate contagion in which clothes played the chief part of vehicles. The customs of the Soudanese lent themselves to this. In the Soudan clothes were almost never washed. The native cloth was woven in narrow strifs which were subsequently sewn together to make a piece. Cloth made in this way did not stand much washing. Rich men bought their clothes new and when they became soiled sold or gave them away. Through the working of this custom any one robe might have during its existence an almost unlimited number of owners, any of whom might have suffered, among other communicable diseases, from leprosy. Natives did not mind buying and wearing robes that had been worn by mutilated lepers. They might even see them stiff with leprous exudations without thinking it necessary to have them washed. Such robes as these they would wear all day and roll about at night with nothing between the prominences of their bodies and the hard matted surfaces which serred them as beds but these leprous garments. Mr. Tonkin applied these facts to the explanation of the mode of dissemination of the disease by pointing out that it was exactly upon those prominences that (in the Soudan at least) the first sign of the disease most usually appeared. In attempting to account for the predisposition to leprosy $\mathbf{M r}$. Tonkin laid down what he referred to as the anitrogenous theory. In every leper field in the world if the average diet of the affected classes were tabulated it would in each case probably present the same specific defect. That defect was the lack of a sufficient quantity of nitrogenous elements. To 